\title{
Change in responsiveness of rabbit corpus luteum to prostaglandin F-2 $\alpha$ during pregnancy and pseudopregnancy
}

\author{
J. L. Marcinkiewicz ${ }^{1}$, E. S. Moy ${ }^{2}$ and J. M. Bahr ${ }^{1 *}$ \\ ${ }^{1}$ Department of Animal Sciences, University of Illinois, Urbana, USA; ${ }^{2}$ Department of Obstetrics \\ and Gynecology, Washington University Medical School, St Louis, USA
}

\begin{abstract}
Summary. Previous studies have suggested that prostaglandin F-2 $\alpha$ (PGF-2 $\alpha$ ) may have a role in luteolysis in rabbits. Rabbits (4-6/group) were given a single injection of saline, or 100,500 or $2500 \mu \mathrm{g}$ PGF-2 $\alpha$ (i.m.) on Day 7, 9, 12 or 15 of pregnancy or pseudopregnancy. Daily blood samples were taken via the marginal ear vein before and for 3 days after the PGF-2 $\alpha$ injection. Concentrations of serum progesterone were determined by radioimmunoassay in pseudopregnant rabbits. There were no significant differences between PGF-2 $\alpha$-treated and control rabbits on Days 7 or 9. On Day 12 of pseudopregnancy, progesterone concentration was significantly $(P<0.05)$ lower in treated than in control rabbits, the effect being dose dependent. On Day 15 of pseudopregnancy, it was not possible to distinguish between controls and treated groups because luteolysis occurred in all rabbits.

In contrast, on Days 7 and 9 of pregnancy, the concentration of progesterone in treated groups was lower than in the control groups $(P<0.05)$, the effect being dose dependent. This difference was maintained throughout the sampling period and resulted in termination of pregnancy. By Day 12 of pregnancy, the response to PGF- $2 \alpha$ was transient, with a significant decline in progesterone for only 2 days, followed by a return to control concentrations and normal delivery of litters. On Day 15 of pregnancy, no treatment with PGF-2 $\alpha$ significantly altered progesterone concentration. Our results indicate that (i) there is a change in responsiveness to PGF- $2 \alpha$ over time during pregnancy and pseudopregnancy and (ii) there are differences between pregnancy and pseudopregnancy in the pattern of responsiveness.
\end{abstract}

Keywords: corpus luteum; prostaglandin F-2 $\alpha$; pregnancy; pseudopregnancy; rabbit

\section{Introduction}

The corpus luteum $(\mathrm{CL})$ of pregnant rabbits produces high concentrations of progesterone for 30-32 days, but in pseudopregnancy the $C L$ is functional for only 16-18 days. Maternal recognition of pregnancy occurs on Day 12 post coitum (Nowak \& Bahr, 1983), and it is then that the CL of pseudopregnant rabbits begins to regress. The rabbit conceptus prolongs the life of the CL through an unknown mechanism, but probably by production of luteotrophic and/or antiluteolytic factors.

The factors which cause regression of the $\mathrm{CL}$ of pseudopregnancy are not fully understood. The uterus may have a role in luteolysis; pseudopregnancy was partially extended for 6-8 days by hysterectomy (Scott \& Rennie, 1970; Hilliard, 1973). Uterine PGF-2 $\alpha$ is responsible for luteolysis in many species (see Goldberg \& Ramwell, 1975 and Knickerbocker et al., 1988 for reviews). An intraovarian mechanism may also be involved in luteolysis, as the ovary is a source of prostaglandins (Miller et al., 1983; Schlegel et al., 1988). Administration of exogenous PGF-2a caused luteolysis in pseudopregnant rabbits (Gutknecht et al., 1972; Keyes \& Bullock, 1974;

*Reprint requests. 
Carlson \& Gole, 1978; Kehl \& Carlson, 1981) and pregnant rabbits (Koering \& Kirton, 1973). Inhibition of prostaglandin synthesis by indomethacin extended pseudopregnancy (O'Grady et al., 1972) and delayed parturition in pregnant rabbits (Nathanielsz et al., 1972).

Prostaglandin F-2 $\alpha$ has been measured in uterine venous plasma in rabbits (Lytton \& Poyser, 1982). Concentrations in the uterine vein are similar in pregnant and pseudopregnant rabbits until Day 17, when the concentrations in pseudopregnant rabbits are significantly greater than those in the pregnant doe (Lytton \& Poyser, 1982). On Day 15, concentration of PGF-2 $\alpha$ in the ovaries is significantly higher in pseudopregnant than in pregnant rabbits (Schlegel et al., 1988). Concentrations of progesterone and PGF-2 $\alpha$ during pseudopregnancy are inversely related except that the decline in progesterone occurs before the increase in PGF- $2 \alpha$, which might suggest that PGF- $2 \alpha$ itself does not initiate luteolysis. Alternatively, there may be a change in the responsiveness of the CL to the effects of PGF- $2 \alpha$ over time, such that even low concentrations of PGF- $2 \alpha$ can initiate luteolysis.

This experiment determined whether the responsiveness of the CL to PGF-2 $\alpha$ changes during pseudopregnancy and pregnancy in rabbits, especially in relation to the time of maternal recognition of pregnancy.

\section{Materials and Methods}

\section{Animals and treatment}

Does were housed individually in an indoor facility. Oestrous does were mated (designated Day 0 ) to either an intact buck to induce pregnancy or to a vasectomized buck to induce pseudopregnancy. Animals were randomly grouped (4-6 rabbits/group) in a $4 \times 4 \times 2$ factorial design, with day of injection, dose of PGF-2 $\alpha$ and pregnancy status as the factors. On the day of treatment, a blood sample was collected via the marginal ear vein followed by a single intramuscular injection of 0 (saline), 100, 500 or $2500 \mu \mathrm{g}$ PGF-2 $\alpha$ (Lutalyse: UpJohn Company, Kalamazoo, MI, USA). These doses were chosen because previous studies in rabbits have demonstrated that injection of 1-2 mg PGF-2 $\alpha$ induces luteolysis (Gutknecht et al., 1972; Koering \& Kirton, 1973; Keyes \& Bullock, 1974; Carlson \& Gole, 1978). Blood samples were taken at intervals of $24 \mathrm{~h}$ for 3 days. Each of the doses of PGF-2 $\alpha$ was given on Days 7, 9 , 12 and 15 of pregnancy and pseudopregnancy. Effects of treatment were determined by changes in concentrations of serum progesterone.

\section{Hormone measurement}

Serum was assayed for progesterone by radioimmunoassay, according to the procedure of Bahr et al. (1980). Progesterone was extracted from the serum with petroleum ether and the efficiency of the extraction procedure was monitored by addition of $\left[{ }^{3} \mathrm{H}\right]$ progesterone. Each sample was corrected for recovery of label. Intra- and interassay coefficients of variation were $8 \cdot 6$ and $10 \cdot 4 \%$, respectively.

\section{Statistical analysis}

Significant differences were determined by multivariate repeated-measures analysis of variance. Progesterone concentrations in response to each dose of PGF-2 $\alpha$ were compared with controls on each day of treatment. Differences were considered significant if $P<0.05$. Multiple linear regression of dose on progesterone was also done to determine whether effects of PGF-2 $\alpha$ were dose dependent. Regression lines with a negative slope and correlation of $>0.3$ and $P<0.05$ were considered significant. All statistics were performed using the Systat statistics package (Wilkinson, 1988).

\section{Results}

\section{Pseudopregnancy}

On Days 7 and 9 of treatment (Fig. 1a, b), there was no effect of PGF-2 $\alpha$ on progesterone $(P>0.05)$ in pseudopregnant rabbits; on Day 12 (Fig. 1c), progesterone concentrations were significantly lower than in controls $24 \mathrm{~h}$ after injection with $2500 \mu \mathrm{g}$ of PGF- $2 \alpha(P<0 \cdot 1)$. This 
(a) Day 7

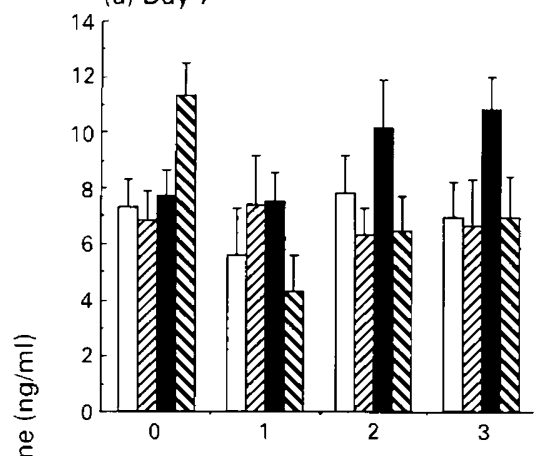

(c) Day 12

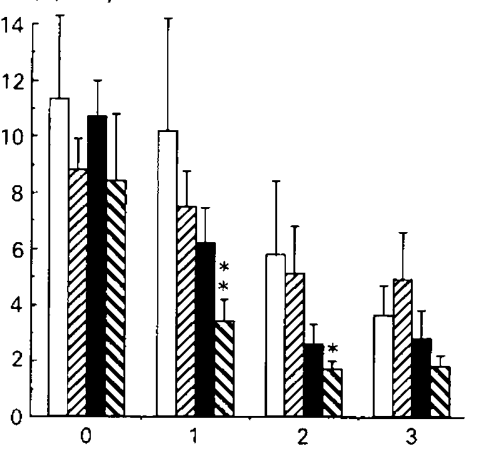

(b) Day 9

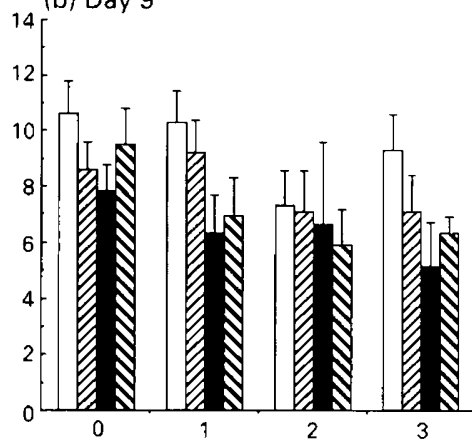

(d) Day 15

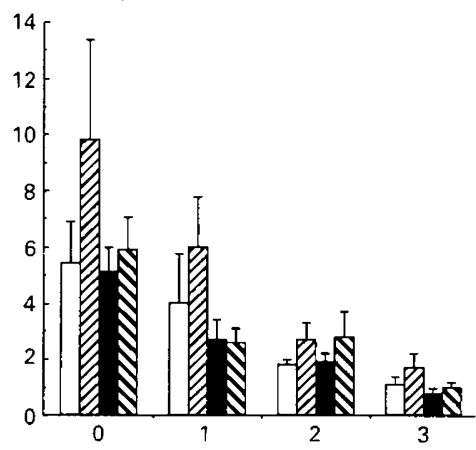

Days after injection

Fig. 1. Concentrations (mean \pm SEM) of serum progesterone after treatment of rabbits with 0 (口), $100\left(\mathbb{Z}_{\triangle}\right), 500(\boldsymbol{\square})$ or $2500(\mathbb{\mathbb { S }}) \mu \mathrm{g}$ prostaglandin $\mathrm{F}-2 \alpha$ on Day 7 (a), 9 (b), 12 (c) or 15 (d) of pseudopregnancy; significant difference from control at ${ }^{*} P<0.05$ and ${ }^{* *} P<0.01, n=4-6$.

difference was also observed on Day 2 after treatment $(P<0.05)$, but was absent by Day 3, because control CL were also regressing at this time. There was a significant relationship between dose of PGF-2 $\alpha$ and response of progesterone concentration on Day 12 after treatment $(P<0 \cdot 05)$. By Day 15 of pseudopregnancy (Fig. 1d), there was no longer a significant effect of PGF-2 $\alpha$ on progesterone, which declined in all groups over time because of inherent luteolysis.

\section{Pregnancy}

On Day 7 of pregnancy (Fig. 2a), concentrations of progesterone were lower in rabbits treated with PGF- $2 \alpha$ than in the controls. Progesterone concentration was significantly lower than in controls $(P<0.05)$ on all days after treatment in rabbits given $2500 \mu \mathrm{g}$ PGF- $2 \alpha$ and on Days 2 and 3 after treatment in those treated with $500 \mu \mathrm{g}$ of PGF-2 $\alpha$. The effect of dose of PGF- $2 \alpha$ on progesterone was highly significant $(P<0.005)$. Similarly, treatment with $2500 \mu \mathrm{g}$ PGF-2 $\alpha$ on Day 9 of pregnancy (Fig. 2b) significantly lowered progesterone concentration compared with controls $(P<0.05)$. Regression analysis showed that progesterone concentrations were dependent on dose of PGF-2 $\alpha(P<0.001)$. On Days 7 and 9 , significant decreases in progesterone resulted in termination of pregnancy within 24-48 h. Termination of pregnancy was observed as expulsion of fetal membranes or presence of bloody discharge either in the cage or on the doe. On Day 12 of pregnancy (Fig. 2c), $2500 \mu \mathrm{g}$ PGF-2 $\alpha$ transiently reduced progesterone concentration for 2 days after administration $(P<0.05)$. However, by 3 days after treatment, progesterone had returned to control 
(a) Day 7

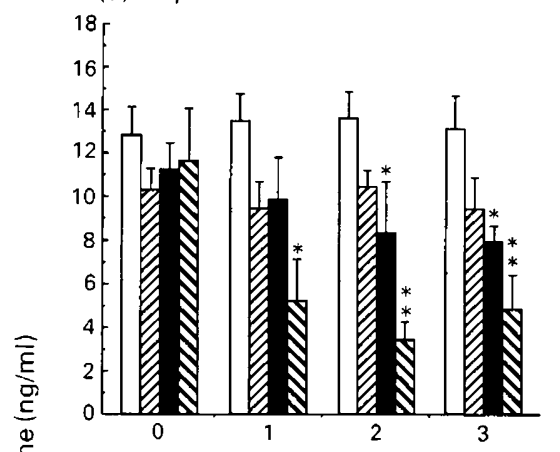

(c) Day 12

(c)

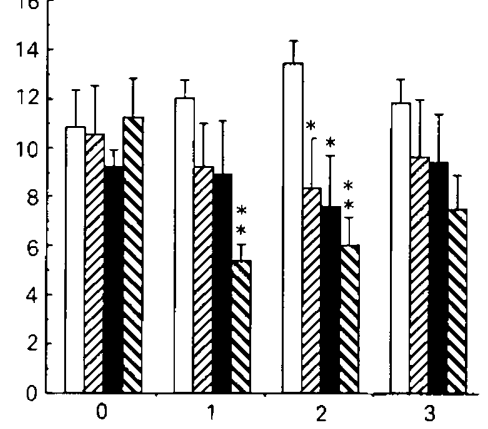

(b) Day 9

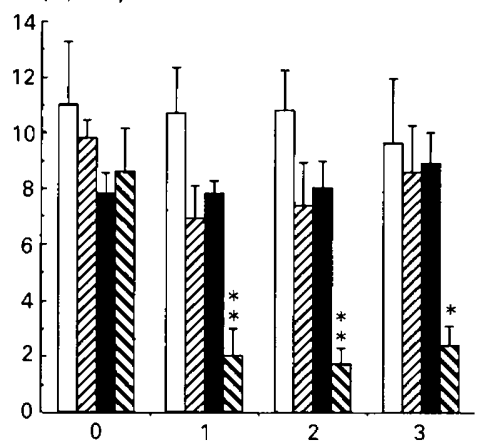

(d) Day 15

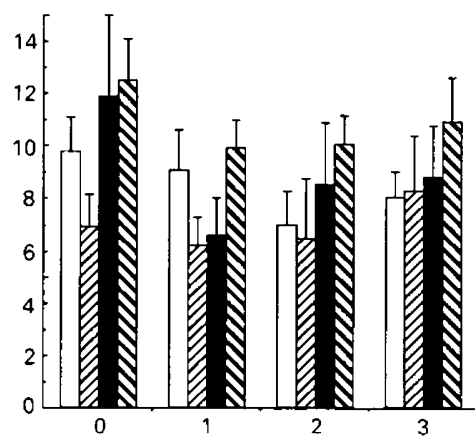

Days after injection

Fig. 2. Concentrations (mean \pm SEM) of serum progesterone after treatment of rabbits with 0

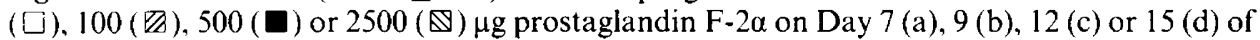
pregnancy; significant difference from control at ${ }^{*} P<0.05$ and ${ }^{*} P<0.01, n=4-6$.

concentrations $(P>0.05)$ and all does delivered normally 30-32 days post coitum. By Day 15 of pregnancy (Fig. 2d), no treatment with PGF-2 $\alpha$ significantly altered progesterone.

\section{Discussion}

This study confirms previous reports of the ability of exogenous PGF-2 $\alpha$ to induce luteolysis in pseudopregnant rabbits (Gutknecht et al., 1972; Keyes \& Bullock, 1974; Carlson \& Gole, 1978; Kehl \& Carlson, 1981). In three previous reports, when PGF-2 $\alpha$ treatments were initiated on Day 9 of pseudopregnancy, daily injections of 1-2 mg PGF- $2 \alpha$ for 3 days (Keyes \& Bullock, 1974), injections of $500 \mu \mathrm{g} \mathrm{PGF}-2 \alpha$ twice a day for 4 days (Gutknecht et al., 1972) or constant infusion of $25 \mu \mathrm{g}$ PGF-2 $\alpha$ into the jugular vein for $6 \mathrm{~h}$ (Kehl \& Carlson, 1981) induced luteolysis after 2 days of treatment. Unlike the present study, these authors observed luteolysis in Day 9 pseudopregnant does. However, in each of these studies, duration of exposure to PGF-2 $\alpha$ was potentially much longer than in the current study. Higher effective doses of PGF- $2 \alpha$ may be needed for an effect early in pseudopregnancy because the lungs are capable of metabolizing $>90 \%$ of the prostaglandins in a single pass (Ferreira \& Vane, 1967; Piper et al., 1970). There is evidence that the PGF-2 $\alpha$ metabolite, 13,14-dihydro-PGF-2 $\alpha$, is capable of inducing luteolysis in pseudopregnant rabbits (Kehl \& Carlson, 1981). If the metabolite is the factor directly responsible for luteolysis, this may explain why a high dose of PGF-2 $\alpha$ may be necessary for luteolysis in rabbits, compared with farm animals such as sheep, in which PGF- $2 \alpha$ itself is known to be the luteolytic agent. 
The pattern of response to PGF-2 $\alpha$ in pseudopregnant rabbits supports our original hypothesis that an increase in responsiveness to PGF-2 $\alpha$ might mediate luteolysis. The pseudopregnant rabbits were unresponsive to PGF-2 $\alpha$ before Day 12, when there was a significant dose-dependent effect of PGF- $2 \alpha$ on progesterone concentration. Pigs are also unresponsive to PGF-2 $\alpha$ before Day 12 of the oestrous cycle and this can be correlated with a lack of luteal prostaglandin receptors (Gadsby et al., 1990). Further experiments must be done to determine whether the CL of pseudopregnancy develops responsiveness to PGF- $2 \alpha$ as a result of an increase in PGF- $2 \alpha$ receptors.

The pattern of response to PGF- $2 \alpha$ in pregnant rabbits develops very differently. PGF- $2 \alpha$ had significant dose-dependent effects on Days 7 and 9 of pregnancy and resulted in termination of pregnancy. On Day 12 of treatment, there was a transient decline in progesterone and all does delivered litters normally. By Day 15, there were no effects of PGF- $2 \alpha$ treatment. In effect, pregnant rabbits became less responsive to PGF-2 $\alpha$ and pseudopregnant rabbits more responsive over time. Further experiments must be done to ascertain why pregnant does were responsive to PGF- $2 \alpha$ before Day 12. The conceptus may decrease responsiveness through an effect on the number of PGF $-2 \alpha$ receptors. Alternatively, PGF $-2 \alpha$ may have a deleterious effect on the fetus before complete implantation on Day 12. However, we would expect that fetal death prior to maternal recognition of pregnancy would not induce luteolysis, as removal of the conceptus at these times does not cause a rapid decline in progesterone (Nowak \& Bahr, 1983).

By Day 15 of pregnancy, there was no effect of PGF- $2 \alpha$ on progesterone, suggesting that after maternal recognition of pregnancy, the fetal-placental unit protects the CL from luteolysis. In other species, there is evidence that the fetal-placental unit maintains the CL by suppressing either the production or the responsiveness to PGF-2 $\alpha$, or both. In ewes, the conceptus produces a trophoblastic protein that suppresses production of PGF-2 $\alpha$ by the uterus (Fincher et al., 1986; Knickerbocker et al., 1986). The sheep conceptus also decreases the responsiveness to PGF-2 $\alpha$, administration of PGF- $2 \alpha$ being less effective in pregnant than in nonpregnant ewes (Inskeep et al., 1975; Silvia et al., 1986) and the CL being less responsive to PGF-2 $\alpha$ after maternal recognition of pregnancy (Silvia \& Niswender, 1986). Recently, a protein other than oTP-1 was identified in the sheep trophoblast that is able to inhibit the luteolytic action of PGF-2 $\alpha$ in large luteal cells in vitro (Wiltbank et al., 1990). The rabbit conceptus may act through a similar mechanism to protect the CL from PGF- $2 \alpha$ after maternal recognition of pregnancy.

Our data support the hypothesis that one role of the rabbit conceptus may be to modify ovarian responsiveness to PGF-2 $\alpha$. Our results also suggest that one possible mechanism for luteolysis in pseudopregnant rabbits is an increase in responsiveness to PGF-2 $\alpha$. The conceptus appears to change the responsiveness of the CL as early as Day 7, even though its presence is apparently not necessary for maintenance of the CL until maternal recognition of pregnancy on Day 12. It may be necessary to redefine maternal recognition of pregnancy, because CL function in rabbits differs in pregnant and pseudopregnant rabbits before Day 12. Maternal recognition of pregnancy may involve gradual physiological changes, the expression of which is most evident on Day 12 of pregnancy.

We gratefully acknowledge the expert statistical assistance of $\mathrm{M}$. Hesson-McInnis. This work was supported in part by the University of Illinois Campus Research Board (E. S. Moy) and by NIH grant PHS2RO1HD13037-12 (J. L. Marcinkiewicz). Some of the data were presented at the twenty-first meeting of the Society for the Study of Reproduction, Seattle, Washington, 1988.

\section{References}

Bahr, J.M., Gardner, R. \& Shahabi, N. (1980) Follicular steroidogenesis: effect of reproductive condition. Biol. Reprod. 22, 817-826.

Carlson, J.C. \& Gole, J.W.D. (1978) CL regression in the pseudopregnant rabbit and the effects of treatment with prostaglandin F-2 $\alpha$ and arachidonic acid. $J$. Reprod. Fert. 53, 381-387.

Ferreira, S.H. \& Vane, J.R. (1967) Prostaglandins: their disappearance from and release into circulation. Nature, Lond. 216, 868-873. 
Fincher, K.B., Bazer, F.W., Hansen, P.J., Thatcher, W.W. \& Roberts, R.M. (1986) Ovine conceptus secretory proteins suppress induction of uterine prostaglandinF2 $\alpha$ release by oestradiol and oxytocin. J. Reprod. Fert. 76, 425-433.

Gadsby, J.E., Balapure, A.K., Britt, J.H. \& Fitz, T.A. (1990) Prostaglandin $F-2 \alpha$ receptors on enzymedissociated pig luteal cells throughout the estrous cycle. Endocrinology 126, 787-795.

Goldberg, V.J. \& Ramwell, P.W. (1975) Role of prostaglandins in reproduction. Physiol. Rev. 55, 325-351.

Gutknecht, G.D., Duncan, G.W. \& Wyngarden, L.J. (1972) Inhibition of prostaglandin-F2 $\alpha$ or $\mathrm{LH}$ induced luteolysis in the pseudopregnant rabbit by I7 $\beta$-estradiol. Proc. Soc. Exp. Biol. Med. 139, $406-410$.

Hilliard, J. (1973) Corpus luteum function in guinea pigs, hamsters, rats, mice and rabbits. Biol. Reprod. $\mathbf{8}$, 203-221.

Inskeep, E.K., Smutny, W.J., Butcher, R.L. \& Pexton, J.E. (1975) Effects of intrafollicular injections of prostaglandins in non-pregnant and pregnant ewes. J. Anim. Sci. 41, 1098-1104.

Kehl, S.J. \& Carison, J.C. (1981) Assessment of the luteolytic potency of various prostaglandins in the pseudopregnant rabbit. J. Reprod. Fert. 62, $117-$ 122.

Keyes, P.L. \& Bullock, D.W. (1974) Effects of prostaglandin-F2 $\alpha$ on ectopic and ovarian corpora luted of the rabbit. Biol. Reprod. 10, 519-525.

Knickerbocker, J.J., Thatcher, W.W., Bazer, F.W., Barron, D.H. \& Roberts, R.M. (1986) Inhibition of uterine prostaglandin-F $2 \alpha$ production by bovine conceptus secretory proteins. Prostaglandins 31, $777-793$.

Knickerbocker, J.J., Wiltbank, M.C. \& Niswender, G.D. (1988) Mechanisms of luteolysis in domestic livestock. Dom. Anim. Endocr. 5, 91-107.

Koering, M.J. \& Kirton, K.T. (1973) The effects of prostaglandin-F $2 \alpha$ on the structure and function of the rabbit ovary. Biol. Reprod. 9, 226-245.

Lytton, F.D.C. \& Poyser, N.L. (1982) Concentrations of PGF- $2 \alpha$ and PGE-2 in the uterine blood of rabbits during pseudopregnancy and pregnancy. J. Reprod. Fert. 64, 421-429.

Miller, J.B., Jarosik, C., Stanisic, D. \& Wilson, L. (1983) Alterations in plasma and tissue prostaglandin levels in rabbits during luteal regression. Biol. Reprod. 29, 824-832.

Nathanielsz, P.W., Abel, M. \& Smith, G.W. (1972) Initiation of parturition in the rabbit by intra-aortic infusion of prostaglandin $\mathrm{F} 2 \alpha$. J. Endocr. 55, 617-618.

Nowak, R.A. \& Bahr, J.M. (1983) Effect of embryo removal on concentrations of progesterone and $\mathrm{LH}$ in the rabbit. J. Reprod. Fert. 68, 395-399.

O'Grady, J.P., Caldwell, B.V., Auletta, F.M. \& Speroff, L. (1972) The effects of an inhibitor of prostaglandin synthesis (indomethacin) on ovulation, pregnancy, and pseudopregnancy in the rabbit. Prostaglandins 1, 97-106.

Piper, P.J., Vane, J.R. \& Wyllie, J.H. (1970) Inactivation of prostaglandins by the lungs. Nature 225, $600-604$.

Schlegel, W., Kruger, S., Daniels, D., Fischer, B., Schneider, H.P.G. \& Beier, H.M. (1988) Studies on prostaglandin metabolism in corpora lutea of rabbits during pregnancy and pseudopregnancy. J. Reprod. Fert. 83, 365-370.

Scott, R.S. \& Rennie, P.I.C. (1970) Factors controlling the lifespan of the corpora lutea in the pseudopregnant rabbit. J. Reprod. Fert. 23, 415-422.

Silvia, W.J. \& Niswender, G.D. (1986) Maintenance of the corpus luteum of early pregnancy in the ewe. IV. Changes in luteal sensitivity to prostaglandin F2 $\alpha$ throughout early pregnancy. J. Anim. Sci. 63, 1201-1207.

Wilkinson, L. (1988) SYSTAT: the System for Statistics. Systat, Inc., Evanston, IL.

Wiltbank, M.C. Knickerbocker, J.J., Wiepz, G.J. \& Niswender, G.D. (1990) Ovine conceptal protein blocks the action of prostaglandin F2 $\alpha$ (PGF) on large luteal cells. Biol. Reprod. 42, Suppl. 1, abst 111 .

Received 13 November 1990 